\title{
Increased Epinephrine and Skeletal Muscle Responses to Hypoglycemia in Non-Insulin-dependent Diabetes Mellitus
}

\author{
Harry Shamoon, Seth Friedman, Carlos Canton, Leon Zacharowicz, Meizhu Hu, and Luciano Rossetti \\ Division of Endocrinology and Diabetes Research and Training Center, Albert Einstein College of Medicine, Bronx, New York 10461
}

\section{Abstract}

We evaluated skeletal muscle counterregulation during hypoglycemia in nine subjects with non-insulin-dependent diabetes

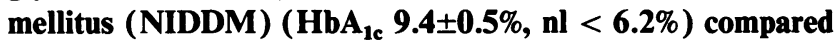
with six normal controls, matched for age ( $51 \pm 3$ and $49 \pm 5 \mathrm{yr}$, respectively $)$ and body mass index $(27.3 \pm 1.2$ and $27.0 \pm 2.1 \mathrm{~kg} /$ $\mathrm{m}^{2}$ ). After $60 \mathrm{~min}$ of euglycemia (plasma insulin $\sim 140 \mu \mathrm{U} /$ $\mathrm{ml}$ ), plasma glucose was lowered to $62 \pm 2 \mathrm{mg} / \mathrm{dl}$ by $120 \mathrm{~min}$. Hypoglycemia induced a 2.2 -fold greater increase in plasma epinephrine in NIDDM $(P<0.001)$, while the plasma glucagon response was blunted $(P<0.01)$. Hepatic glucose output ( $\left[{ }^{3} \mathrm{H}-3\right]$ glucose) suppressed similarly during euglycemia, but during hypoglycemia was greater in $\operatorname{NIDDM}(P<0.005)$. Conversely, glucose uptake during euglycemia was $150 \%$ greater in controls $(P<0.01)$ and remained persistently higher than in NIDDM during hypoglycemia. In NIDDM, plasma FFA concentrations were approximately fivefold greater $(P<0.001)$, and plasma lactate levels were $\sim 40 \%$ higher than in controls during hypoglycemia $(P<0.01$ ); the rates of glycolysis from plasma glucose were similar in the two groups despite a $49 \%$ lower rate of glucose uptake in NIDDM (3.4 \pm 0.9 vs. $6.9 \pm 1.3$ $\mathrm{mg} / \mathrm{kg}$ per minute, $P<0.001)$. Muscle glycogen synthase activity fell by $42 \%$ with hypoglycemia $(P<0.01)$ in NIDDM but not in controls. In addition, glycogen phosphorylase was activated by $56 \%$ during hypoglycemia in NIDDM only ( $P$ $<0.01$ ). Muscle glucose-6-phosphate concentrations rose during hypoglycemia by a twofold greater increment in NIDDM $(P<0.01)$. Thus, skeletal muscle participates in hypoglycemia counterregulation in NIDDM, directly by decreased removal of plasma glucose and, indirectly, by providing lactate for hepatic gluconeogenesis. Consequently, in addition to inherent insulin resistance in NIDDM, the enhanced plasma epinephrine response during hypoglycemia may partially offset impaired glucagon secretion and counteract the effects of hyperinsulinemia on liver, fat, and skeletal muscle. (J. Clin. Invest. 1994. 93:2562-2571.) Key words: hypoglycemia • muscle • glycogen • NIDDM • insulin • epinephrine • glucagon • humans • counterregulation - glycogen synthase - glycogen phosphorylase $\bullet$ glucose- 6 -phosphate $\bullet$ substrates $\bullet$ hepatic glucose output

Address correspondence to Harry Shamoon, M.D., Division of Endocrinology, Albert Einstein College of Medicine, 1300 Morris Park Avenue, Belfer 701, Bronx, NY 10461.

This study was presented in part at the Annual Meeting of the American Diabetes Association in Las Vegas, NV on 14 June 1993.

Received for publication 15 December 1993 and in revised form 16 February 1994.

J. Clin. Invest.

(C) The American Society for Clinical Investigation, Inc.

$0021-9738 / 94 / 06 / 2562 / 10 \quad \$ 2.00$

Volume 93, June 1994, 2562-2571

\section{Introduction}

Hypoglycemia in insulin-dependent diabetes mellitus (IDDM $)^{1}$ seems to result, in part, from defective counterregulation due to deficiencies in secretion of glucagon and epinephrine $(1,2)$. Much less is known about counterregulation of hypoglycemia in non-insulin-dependent diabetes (NIDDM). Since many patients are insulin resistant ( 3 ), it may be that the defect in glucose disposal is inherently protective. On the other hand, when insulin is required for treatment of NIDDM, the doses are generally high and in the range of values capable of suppressing hepatic glucose output (HGO) (4).

In the most comprehensive study of hypoglycemia in NIDDM, moderate experimental hyperinsulinemia suppressed HGO and, together with impairment in glucagon secretion, prevented the hepatic contribution to glucose recovery seen in controls (5). Since a reduction of glucose disposal may compensate for the impaired hepatic response to hypoglycemia in both $\operatorname{IDDM}$ and $\operatorname{NIDDM}(2,5)$, we hypothesized that skeletal muscle would be the major target for glucose counterregulation in the periphery. First, reduction of glucose uptake by muscle would make more glucose available to the brain. Second, the inhibition by insulin of gluconeogenesis from peripherally derived substrates such as lactate may be mediated via reduction of the flux of such substrates to the liver (6). In fact, during hypoglycemia, it is likely that 3-carbon precursors from the peripheral storage pools (i.e., muscle glycogen and adipose tissue) are transferred to the liver to provide substrates for gluconeogenesis.

Lactate and alanine are the two major gluconeogenic precursors in humans (7) and in postabsorptive conditions are mostly derived from the glycolysis of glycogen carbons (8). Under hypoglycemic conditions, muscle glycogenolysis can be expected to depend on the activities of glycogen synthase and glycogen phosphorylase with either $(a)$ activation of phosphorylase; $(b)$ inhibition of synthase; or $(c)$ some combination of both, ultimately resulting in a rise in muscle glucose-6-phosphate (G-6-P) concentrations. The rise in G-6-P could, in turn, buffer the plasma glucose decline by either inhibiting glucose transport or providing precursors for hepatic gluconeogenesis via increased glycolysis of glycogen-derived glucosyl units in muscle. The latter may be a particularly important mechanism for the hepatic response to hypoglycemia in NIDDM since gluconeogenesis accounts for a higher fraction of fasting HGO (9).

We reasoned that coordinated changes in muscle enzyme activities during hypoglycemia would regulate glucose disposal

1. Abbreviations used in this paper: BMI, body mass index; G-6-P, glucose-6-phosphate; GIR, glucose infusion rates; HGO, hepatic glucose output; IDDM, insulin-dependent diabetes mellitus; NIDDM, non-insulin-dependent diabetes mellitus; UDPG, uridine dephosphoglucose. 
and the mobilization of glucosyl units from muscle glycogen. The balance between peripheral insulin action, hormonal/ neuronal counterregulation, and hypoglycemia per se must ultimately control the delivery of gluconeogenic substrates to the liver. In this paper, we evaluated the response of muscle glycogen metabolism to hypoglycemia by combining in vivo glucose kinetics with the measurements of the activities of the rate-limiting enzymes and the muscle concentrations of G-6-P in humans with NIDDM and in controls.

\section{Methods}

\section{Subjects}

Two groups of subjects were studied (Table I). Nine subjects with NIDDM were compared with a group of nondiabetic controls $(n=6)$ matched for age and body mass index (BMI). The NIDDM group (aged $51 \pm 3 \mathrm{yr}$, mean $\pm \mathrm{SE}$ ) was in good health with no evidence of clinically significant diabetic vascular or neuropathic complications. Two subjects were treated with insulin, six with sulfonylurea agents, and one with diet alone; none of the subjects took other medications. They were moderately obese (weight $79.1 \pm 2.8 \mathrm{~kg}$, BMI $27.3 \pm 1.2 \mathrm{~kg}$ / $\mathrm{m}^{2}$ ), were not intensively treated [hemoglobin ( $\left.\mathrm{Hb}\right) \mathrm{A}_{\mathrm{lc}} 9.4 \pm 0.5 \%$, normal $<6.2 \%$ ], and had diagnosed diabetes for an average of $6 \pm 2 \mathrm{yr}$.

The controls were $49 \pm 5 \mathrm{yr}$ of age and similarly obese (weight $80.5 \pm 6.4 \mathrm{~kg}, \mathrm{BMI} 27.0 \pm 2.1 \mathrm{~kg} / \mathrm{m}^{2}$ ). None took medications and all were in good health. One subject with a family history of diabetes had impaired glucose tolerance.

All subjects were assessed with a maximal treadmill exercise test (modified Bruce protocol) before being studied. They were informed of the possible risks of the experiments and gave written informed consent in accord with the regulations of the Albert Einstein College of Medicine.

\section{Experimental procedures}

On the day before study, NIDDM subjects were admitted to the Diabetes Research Unit. Sulfonylurea agents had been discontinued for $\geq 72 \mathrm{~h}$ before. In the subjects who used insulin, long- or intermediateacting preparations were discontinued upon admission. At 10 p.m., a variable short-acting insulin infusion was initiated via a peripheral vein (Humulin Regular ${ }^{\oplus}$; Eli Lilly Co., Indianapolis, IN, diluted in $0.9 \%$ $\mathrm{NaCl}$ with $5 \%$ albumin added) in order to reduce and maintain plasma glucose between 100 and $130 \mathrm{mg} / \mathrm{dl}$ (10). Hypoglycemia was avoided by hourly blood glucose sampling. All subjects were studied after overnight fast.

At 7:00 a.m. on the morning of study, two intravenous cannulae were established, one for infusions and a second inserted retrograde in a dorsal vein of the wrist for blood sampling. Both were kept patent by a slow infusion of $0.9 \% \mathrm{NaCl}$; the hand with the retrograde cannula was kept in a heated box $\left(55^{\circ} \mathrm{C}\right)$ to arterialize venous blood.

In diabetic subjects, the insulin infusion was adjusted to maintain plasma glucose stable during the equilibration period $(111 \pm 4 \mathrm{mg} / \mathrm{dl})$. This insulin infusion rate averaged $0.53 \pm 0.03 \mathrm{mU} / \mathrm{kg}$ per minute. At $t$ $=-120 \mathrm{~min}$, in both controls and NIDDM, a bolus dose $(35 \mu \mathrm{Ci})$ of

Table I. Clinical Characteristics of Study Subjects

\begin{tabular}{lcc}
\hline & $\operatorname{NIDDM}(n=9)$ & Controls $(n=6)$ \\
\hline Age $(y r)$ & $51 \pm 3$ & $49 \pm 5$ \\
Sex $(\mathrm{M} / \mathrm{F})$ & $6 / 3$ & $4 / 2$ \\
Weight $(k g)$ & $79.1 \pm 2.8$ & $80.5 \pm 6.4$ \\
BMI $\left(k g / m^{2}\right)$ & $27.3 \pm 1.2$ & $27.0 \pm 2.1$ \\
Diabetes duration $(y r)$ & $6.4 \pm 2$ & - \\
HbA $_{\text {lc }}(\%)$ & $9.4 \pm 0.5$ & $(\mathrm{nl}<6.2)$ \\
\hline
\end{tabular}

[3- ${ }^{3} \mathrm{H}$ ]glucose (HPLC-purified, sterile solution, New England $\mathrm{Nu}$ clear, Boston, MA) was injected intravenously, followed by a continuous infusion of $0.25 \mu \mathrm{Ci} / \mathrm{min}$ for the remainder of the experiment. At $t$ $=0$, a euglycemic, hyperinsulinemic clamp was initiated in both groups at a constant insulin infusion rate of $40 \mathrm{mU} / \mathrm{m}^{2}$ per minute (priming dose of $80 \mathrm{mU} / \mathrm{m}^{2}$ for $10 \mathrm{~min}$ ). A variable infusion of $20 \%$ dextrose in water, calibrated for the measured glucose concentration and with $\left[3-{ }^{3} \mathrm{H}\right]$ glucose added to a final specific activity of $\sim 0.5 \mu \mathrm{Ci}$ / $\mathrm{mg}$, was used to adjust the plasma glucose concentration according to 5-min determinations. After $60 \mathrm{~min}$ of euglycemic hyperinsulinemia, the glucose infusion rate was reduced to allow a gradual fall of plasma glucose. The clamp was then continued at hypoglycemia for $120 \mathrm{~min}$. The insulin infusion dose was determined from prior studies to achieve a sufficiently high physiologic plasma insulin concentration to produce hypoglycemia in insulin-resistant subjects.

After $60 \mathrm{~min}$ of euglycemic hyperinsulinemia, before the induction of hypoglycemia, a sample of vastus lateralis muscle was excised using a 5-mm Bergstrom-Stille needle using aseptic technique (11). The muscle sample was immediately placed in liquid $\mathrm{N}^{2}$. At $t=180 \mathrm{~min}$, at the end of hypoglycemia, a second muscle sample was obtained and rapidly frozen in liquid $\mathrm{N}^{2}$. The insulin infusion was then discontinued, plasma glucose was raised to euglycemic levels, and the subjects were fed a meal.

From $t=-30 \mathrm{~min}$ to $\mathrm{t}=180 \mathrm{~min}, 5-10-\mathrm{min}$ samples of blood were obtained for determination of plasma glucose, insulin, glucagon, epinephrine, norepinephrine, free fatty acids, lactate, cortisol, and growth hormone. Additional samples for $\left[3-{ }^{3} \mathrm{H}\right]$ glucose and ${ }^{3} \mathrm{H}_{2} \mathrm{O}$ determinations were also obtained. Plasma for the insulin determinations was immediately precipitated in polyethylene glycol as previously described (12).

\section{Measurements}

The methods for determination of plasma glucose, insulin, glucagon, epinephrine, norepinephrine, cortisol, growth hormone, and free fatty acids have been previously described $(13,14)$. Plasma lactate was measured using an enzymatic spectrophotometric assay (15). The determination of glucose specific activity from deproteinized plasma using the Somogyi method and calculation of glucose turnover using Steele's equation modified for nonsteady state has been previously published (16). The method of Finegood and Vranic was used to reduce the decline in glucose specific activity by employing the so-called "hot" glucose infusate technique (17). Plasma tritiated water specific activity was determined by liquid scintillation counting of the protein-free supernatant (Somogyi filtrate) before and after evaporation to dryness. Because tritium on the C-3 position of glucose is lost to water during glycolysis, it can be assumed that plasma tritium is present either in tritiated water or $\left[3-{ }^{3} \mathrm{H}\right]$ glucose $(18,19)$. Although tritium may also be released during fructose-6-phosphate cycling and/or pentose phosphate cycling, these pathways account for only a small percentage of glucose turnover (20-22). Additionally, some of the glucose carbons that enter the pentose phosphate pathway will re-enter the glycolytic pathway through glyceraldehyde and will be correctly interpreted as glycolytic flux with the present methodology. Rates of glycolysis from plasma glucose were thus estimated from the increment per unit time in tritiated water $(\mathrm{dpm} / \mathrm{ml} \cdot \min ) \times$ body water mass $(\mathrm{ml}) /\left[3-{ }^{3} \mathrm{H}\right]-$ glucose specific activity $(\mathrm{dpm} / \mathrm{mg})$. The methodology for estimating whole-body glycolysis from plasma glucose has been previously validated in humans under euglycemic conditions of fasting insulinemia or hyperinsulinemia (23). Muscle G-6-P concentrations were measured spectrophotometrically as described by Michal (24).

Glycogen synthase. Muscle glycogen synthase activity was measured by a modification (24-26) of the method of Thomas et al. (27) and is based on the measurement of the incorporation of radioactivity into glycogen from uridine dephosphoglucose (UDP)-[U- $\left.{ }^{14} \mathrm{C}\right]-$ glucose. Tissue samples $(7-12 \mathrm{mg})$ were homogenized in $1.0 \mathrm{ml}$ of Tris/HCl buffer, pH 7.8, containing $10 \mathrm{mM}$ EDTA, $5 \mathrm{mM}$ DTT, 50 $\mathrm{mM} \mathrm{NaF}$, and $2.5 \mathrm{~g} /$ liter rabbit liver glycogen Type III. The homogenate was centrifuged at $2,000 \mathrm{~g}$ for $15 \mathrm{~min}\left(\right.$ at $\left.4^{\circ} \mathrm{C}\right)$, and the superna- 
tant was used for glycogen synthase assay by measuring the incorporation of UDP- $\left[\mathrm{U}-{ }^{14} \mathrm{C}\right]$ glucose into glycogen at $37^{\circ} \mathrm{C}$. Synthase activity was assayed in the presence of 0.11 and $0.22 \mathrm{mM} \mathrm{G-6-P.} \mathrm{Total} \mathrm{enzyme}$ activity was measured in the presence of $7.2 \mathrm{mM} \mathrm{G-6-P.} \mathrm{For} \mathrm{the} \mathrm{kinetic}$ analysis, the assay was conducted at final concentrations of 0.003 , $0.017,0.033,0.09,0.33$, and $1.4 \mathrm{mM}$ UDPG; the data were linearized as Eadie-Hofstee plots and fitted using a linear-regression model. The $K_{\mathrm{m}}$ for UDPG is the reciprocal of the slope, whereas $V_{\max }$ is the $y$-intercept divided by the slope. To approximate the in vivo conditions, incubations were also carried out in presence of the UDPG $(5-50 \mu \mathrm{M})$ and G-6-P (50-250 $\mu \mathrm{M})$ concentrations physiologic for human skeletal muscle. However, this in vitro estimate may not fully account for allosteric modification of the enzyme activity occurring in vivo.

Glycogen phosphorylase. Muscle glycogen phosphorylase activity was measured as previously described $(24,28)$. This assay is based on the measurement of the incorporation of carbon- 14 into glycogen from labeled G-1-P. Glycogen phosphorylase $a$, the active phosphorylated enzyme, was assayed in the absence of AMP, and phosphorylase $b$, the total enzyme activity, was assayed in the presence of $5 \mathrm{mM}$ AMP. Tissue homogenates $(7-12 \mathrm{mg})$ were prepared as described above. The supernatant was used for glycogen phosphorylase assay by measuring the incorporation of ${ }^{14} \mathrm{C}-\mathrm{G}-1-\mathrm{P}$ into glycogen at $30^{\circ} \mathrm{C}$ in a mixture containing $33 \mathrm{mM}$ MES, $200 \mathrm{mM} \mathrm{KF}, 0.45 \%$ mercaptoethanol, 15 $\mathrm{mM} \mathrm{G}-1-\mathrm{P}(50 \mu \mathrm{Ci} / \mathrm{mmol})$, and $3.4 \mathrm{mg} / \mathrm{ml}$ glycogen. Phosphorylase $b$ was assayed in the same manner except that the mixture contained 100 $\mathrm{mM} \mathrm{G}-1-\mathrm{P}(6 \mu \mathrm{Ci} / \mathrm{mmol}), 13.4 \mathrm{mg} / \mathrm{ml}$ glycogen, and $5 \mathrm{mM}$ AMP.

\section{Statistical analyses}

The data are presented in the text and figures as means \pm SE. The results over time were compared using ANOVA with repeated measures while the differences between specific points were examined by two-tailed $t$ tests (29). A $P$ value $<0.05$ was considered significant.

\section{Results}

\section{Plasma glucose and insulin}

The plasma glucose and insulin concentrations during the clamps are depicted in Fig. 1. As designed, the initial fasting plasma glucose concentrations in NIDDM subjects were $\sim 20-30 \%$ higher. This was achieved (by overnight insulin infusion rates averaging $3.5 \pm 1 \mathrm{U} / \mathrm{h}$ ) in order to provide moderate insulinization and to avoid the rise in counterregulatory hormones that might have been provoked even at near-normoglycemia. Subsequent to the insulin infusion, plasma glucose in the two groups converged and were not significantly different from each other from +15 min onwards. Plasma insulin concentrations were higher in NIDDM before the clamps $(P<0.005$, Fig. 1). During the clamps, plasma insulin levels were similar in the two groups.

\section{Plasma counterregulatory hormones and C-peptide concentrations}

Plasma concentrations of the major counterregulatory hormones and of C-peptide are depicted in Fig. 2. Plasma epinephrine at baseline was slightly greater in $\operatorname{NIDDM}(P<0.05)$. As plasma glucose was further lowered in NIDDM to the euglycemic clamp plateau, plasma epinephrine doubled, while in controls it remained unchanged. When hypoglycemia was induced, the increase in plasma epinephrine occurred in both groups; by the final 30 min of hypoglycemia, however, plasma epinephrine was 2.2-fold higher in NIDDM compared with controls $(P<0.001)$.

The pattern for the changes in plasma glucagon was more complex. Baseline plasma glucagon concentrations were slightly higher in NIDDM $(P=\mathrm{NS})$ and tended to decline
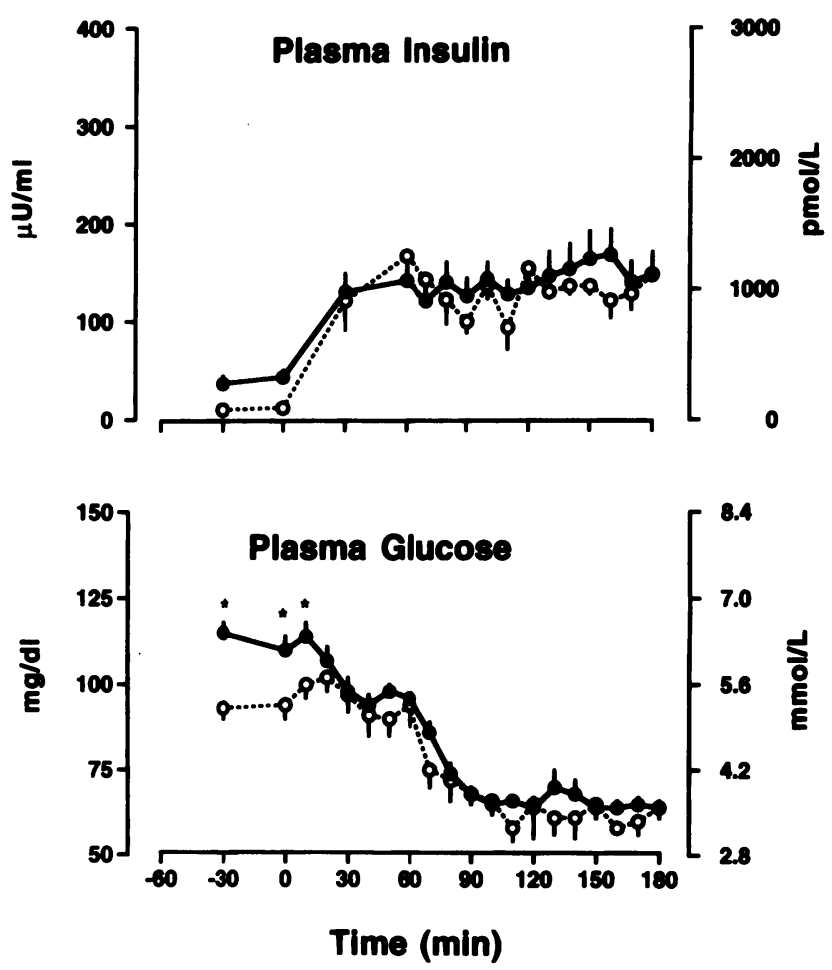

Figure 1. Plasma glucose and insulin concentrations during clamp studies in control subjects $(0)$ and NIDDM patients $(\bullet)$. Before hypoglycemia, plasma glucose concentration was significantly greater in $\operatorname{NIDDM}\left({ }^{*} P<0.001\right)$.

during euglycemia in both groups. During hypoglycemia, plasma glucagon increased by $50-100 \%$ above basal in controls, while no significant increase was observed in $\operatorname{NIDDM}(P$ $<0.01$ ). The changes in the remaining counterregulatory hormones (norepinephrine, cortisol, and growth hormone) were similar in the two groups, although plasma cortisol increased to greater absolute concentrations in $\operatorname{NIDDM}(P<0.05$, Fig. 2$)$. Plasma C-peptide concentrations were higher at baseline in controls compared with NIDDM $(P<0.05)$. In both groups, there was a decline throughout the study, and by the end of the hypoglycemic period the values in NIDDM converged with those in controls. $\beta$-cell secretion was not completely suppressed in either group at this degree of moderate hypoglycemia.

\section{Glucose turnover}

[3- $\left.{ }^{3} \mathrm{H}\right]$ glucose specific activities were effectively maintained in both groups during the clamps (Fig. 3). The difference between the highest and lowest specific activities was $<20 \%$ in both control and NIDDM throughout the basal, euglycemic, and hypoglycemic periods. HGO (Fig. 4) was identical in the two groups before the clamps, averaging $2.01 \pm 0.31 \mathrm{mg} / \mathrm{kg}$ per minute in controls and $2.11 \pm 0.18 \mathrm{mg} / \mathrm{kg}$ per minute in NIDDM. During euglycemia, HGO was similarly suppressed by insulin to values essentially indistinguishable from zero ( 3 normal and 2 NIDDM had small negative values calculated during this period). Thereafter, as hypoglycemia was initiated, HGO began to increase in NIDDM to levels $\sim 40 \%$ of basal while it remained suppressed in controls $(P<0.005)$. During hypoglycemia, HGO was greater in NIDDM than in controls. In contrast, glucose uptake was stimulated during euglycemia by a 

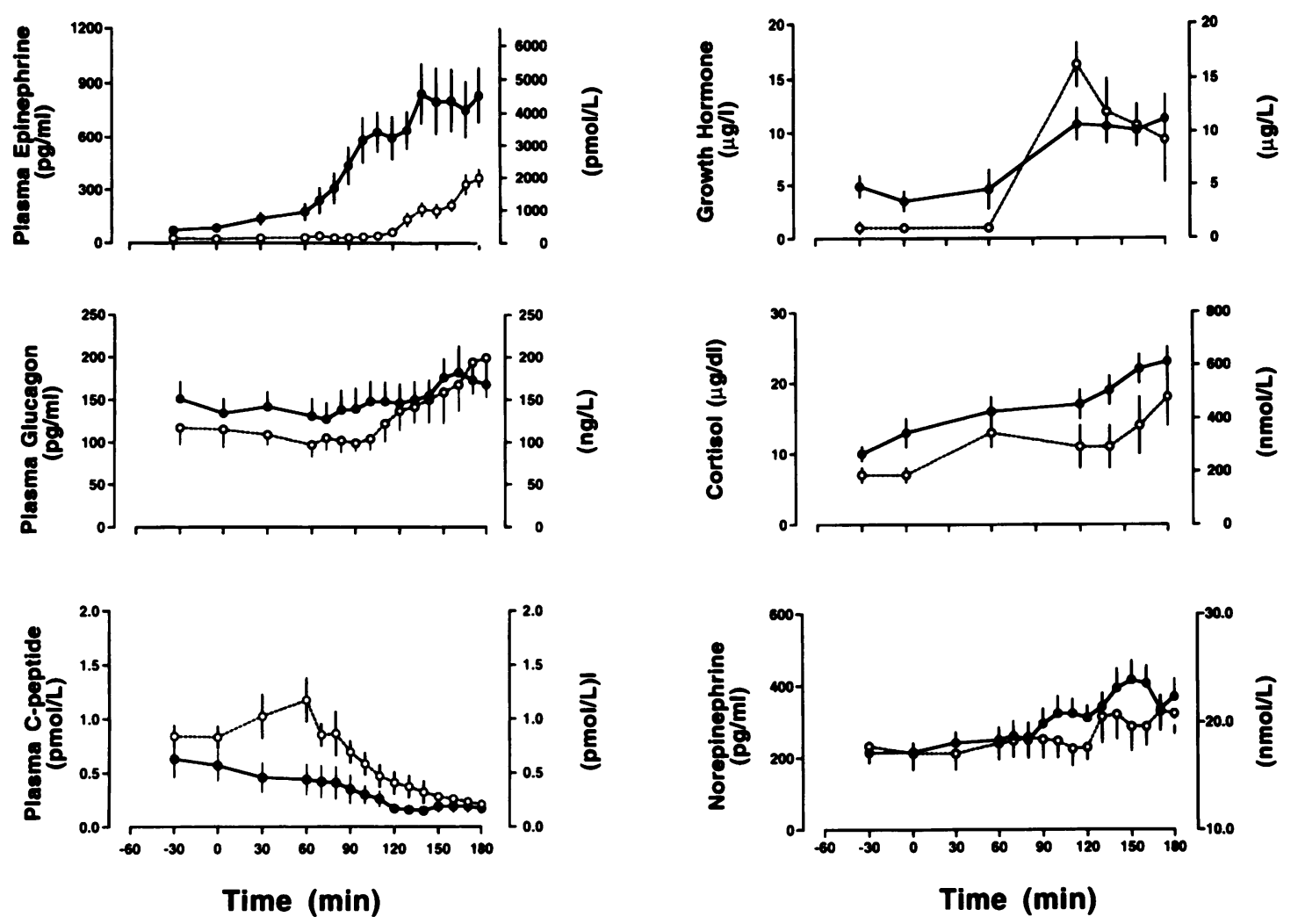

Figure 2. Plasma counterregulatory hormone and C-peptide concentrations in controls ( $)$ ) and NIDDM (•). The increase in plasma epinephrine during hypoglycemia was greater in NIDDM compared with controls, whereas the controls demonstrated an increase in plasma glucagon greater than that in NIDDM ( see text for details). Plasma C-peptide concentrations were higher in controls during the euglycemic portion of the study but were suppressed to comparable concentrations by the final period of hypoglycemia.
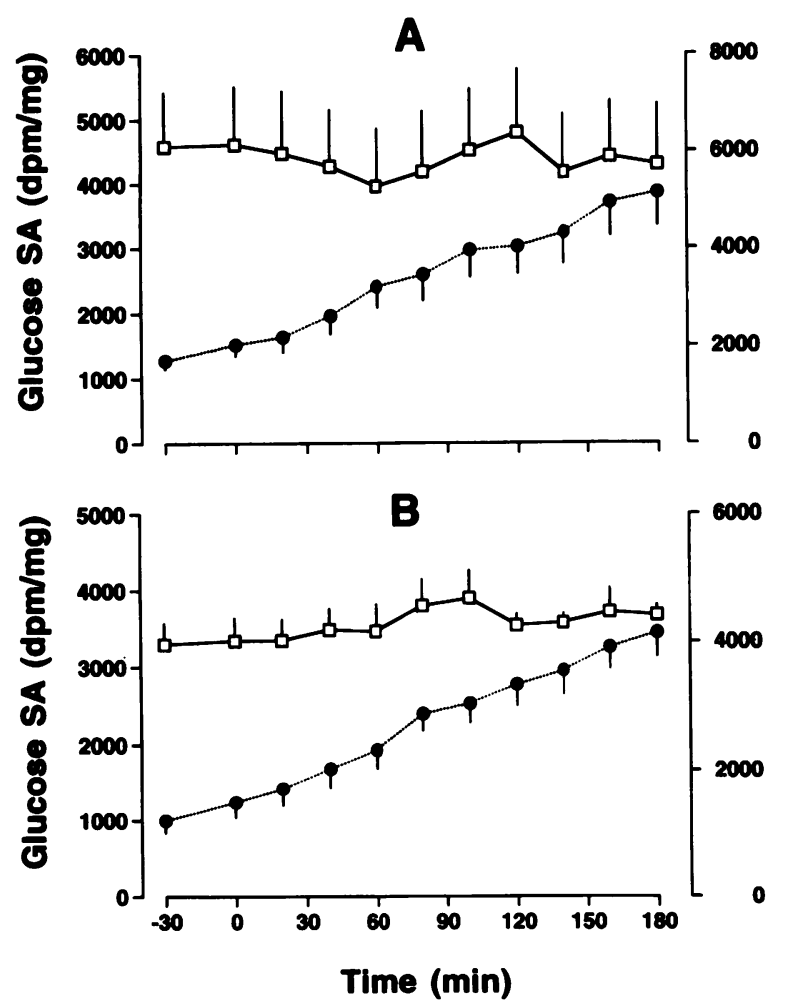

Figure 3. Plasma specific activities of $\left[{ }^{3} \mathrm{H}-3\right]$ glucose $(\square)$ and ${ }^{3} \mathrm{H}_{2} \mathrm{O}(\bullet)$ in controls $(A)$ and NIDDM $(B)$ during the study period (see text for details).
$150 \%$ greater increase in controls versus NIDDM $(P<0.01)$, although in both groups glucose uptake increased above baseline. During hypoglycemia, glucose uptake fell to near baseline values in NIDDM $(P=\mathrm{NS})$; in controls, the decrease was less pronounced and even by the end of hypoglycemia it remained threefold above baseline. Glucose infusion rates (GIR) paralleled these changes in glucose uptake. Reflecting their peripheral insulin resistance, NIDDM required a maximal GIR of only $66 \%$ that of controls $(P<0.05)$, with these requirements falling substantially during the hypoglycemia as endogenous counterregulation occurred. By the final $60 \mathrm{~min}$, GIR averaged $2.73 \pm 1.27 \mathrm{mg} / \mathrm{kg}$ per minute in NIDDM, accounting for $79 \%$ of total glucose disposal. In contrast, during this same period normals required an almost twofold higher GIR to maintain glycemia and this was $99 \%$ of total glucose disposal.

Plasma substrate concentrations and ${ }^{3} \mathrm{H}_{2} \mathrm{O}$ specific activity Plasma FFA (Fig. 5) was higher at baseline in NIDDM, although not significantly. With institution of the clamp, plasma FFA fell promptly in controls and continued to decline even during hypoglycemia while in NIDDM, the insulin-induced suppression never reached the absolute plasma FFA concentrations in controls $(P<0.001)$. By the end of hypoglycemia, plasma FFA was almost fivefold greater in NIDDM.

Plasma lactate concentrations were identical in the two groups at baseline (Fig. 5) and rose in a very similar pattern during euglycemic hyperinsulinemia by $\sim 25 \%$ over basal. Upon induction of hypoglycemia, however, the two groups diverged with plasma lactate in controls being consistently $\sim 0.6$ 

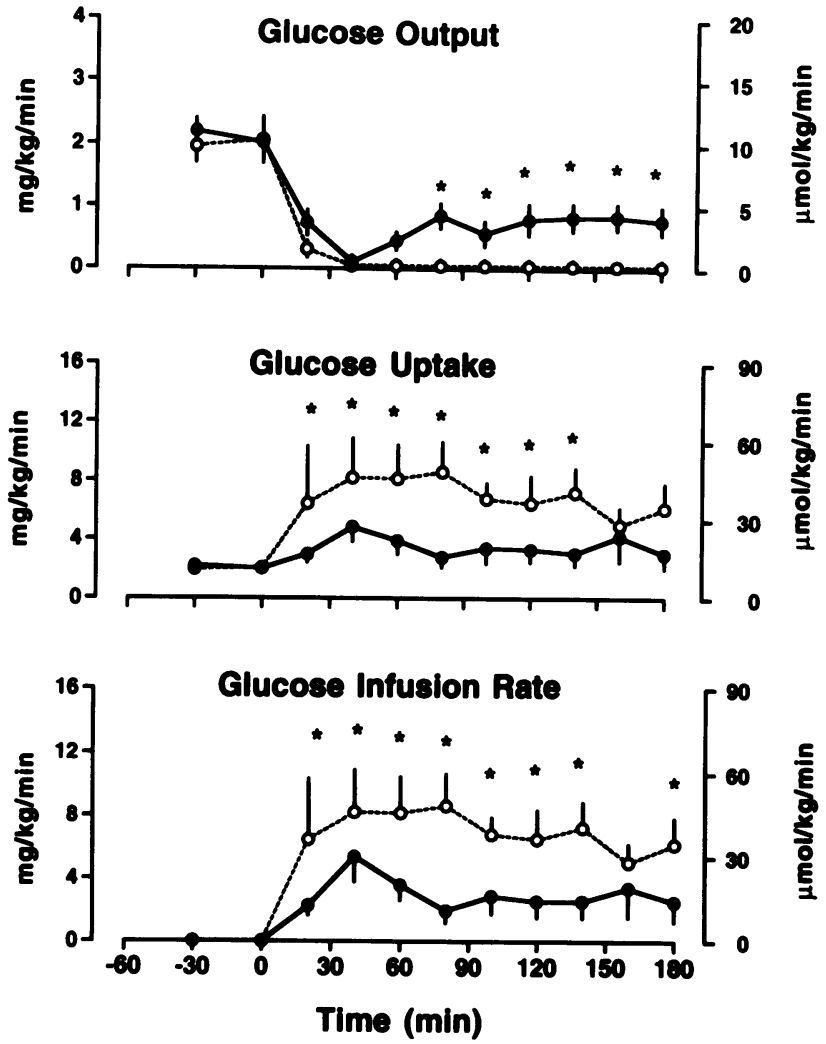

Figure 4. Glucose turnover in control subjects (O) and NIDDM patients $(\bullet)$. During hypoglycemia, glucose output was greater in NIDDM from 80 min onwards $\left({ }^{*} P<0.005\right)$, while glucose uptake was greater in controls between 20 and $140 \mathrm{~min}\left({ }^{*} P<0.01\right)$, spanning both the euglycemic and hypoglycemic periods. Glucose infusion rates were also significantly higher in controls $\left({ }^{*} P<0.05\right)$ during this time.

$\mathrm{mM}$ lower than in NIDDM for the final $60 \mathrm{~min}$ of hypoglyce$\operatorname{mia}(P<0.01)$.

An estimate of the rate of glycolysis from plasma glucose was obtained from the specific activities of plasma $\left[3-{ }^{3} \mathrm{H}\right]-$ glucose and plasma ${ }^{3} \mathrm{H}_{2} \mathrm{O}$ (Fig. 3). A constant, virtually linear, increase in plasma ${ }^{3} \mathrm{H}_{2} \mathrm{O}$ specific activity occurred in both groups during hypoglycemia. Despite a $\sim 50 \%$ lower rate of glucose uptake in NIDDM subjects $(3.4 \pm 0.9$ vs. $6.9 \pm 1.3 \mathrm{mg}$ / $\mathrm{kg} \cdot \min ; P<0.001$ ), the mean rate of flux of plasma glucose through glycolysis during the hypoglycemic clamp study was similar in NIDDM $(2.3 \pm 0.2 \mathrm{mg} / \mathrm{kg} \cdot \mathrm{min})$ and controls $(2.1 \pm 0.2 \mathrm{mg} / \mathrm{kg} \cdot \min )$.

\section{Skeletal muscle glycogen synthase and phosphorylase activities and G-6-P concentrations}

Figs. 6-8 and Table II depict the results of the skeletal muscle analyses conducted at the end of euglycemic hyperinsulinemia and again after hypoglycemia. Representative Eadie-Hofstee plots of glycogen synthase activity in one control and one NIDDM subject are shown in Fig. 6. During euglycemia, glycogen synthase activity was reduced in NIDDM at all in vitro concentrations of G-6-P. After $120 \mathrm{~min}$. of hypoglycemia, there was little or no change in the enzyme's activity in controls but a $30-40 \%$ decline was observed in NIDDM (Table II). When expressed as the glycogen synthase activity at mid-physiologic concentrations of G-6-P $(110 \mu \mathrm{M})$ and UDPG $(33 \mu \mathrm{M})$, the decrease in NIDDM from euglycemic values averaged $42 \%$ $(P<0.01)$ while in control subjects there was no decrease in enzyme activity (Fig. 7).

Skeletal muscle glycogen phosphorylase activity was also differentially affected by hypoglycemia in NIDDM subjects. When expressed as the ratio of phosphorylase $a / b$ activity, the baseline values were very similar for NIDDM and control subjects (Fig. 7). During hypoglycemia, however, there was a 56\% activation of skeletal muscle phosphorylase in NIDDM, but none in controls $(P<0.01)$.

Finally, the results of the intracellular G-6-P determinations are shown in Fig. 8. At baseline euglycemic hyperinsulinemia, skeletal muscle G-6-P concentrations were similar in the two groups at $\sim 200-250 \mathrm{nmol} / \mathrm{g}$ wet wt. During hypoglycemia, consistent with the inhibition of glycogen synthase and the stimulation of glycogen phosphorylase activities, there was a fivefold increase in skeletal muscle G-6-P concentrations in the NIDDM. The magnitude of this rise was approximately twofold greater than in controls $(P<0.01)$.

\section{Discussion}

Our results suggest that at plasma insulin concentrations high enough to produce mild hypoglycemia in conventionally treated NIDDM subjects (albeit on varying treatment regimens), the overall counterregulatory response is more vigorous than in age- and weight-matched controls. During hypoglycemia, HGO remained completely suppressed in the controls, but rose to $\sim 40 \%$ of the basal level in the NIDDM. Furthermore, despite hyperinsulinemia, whole body glucose uptake
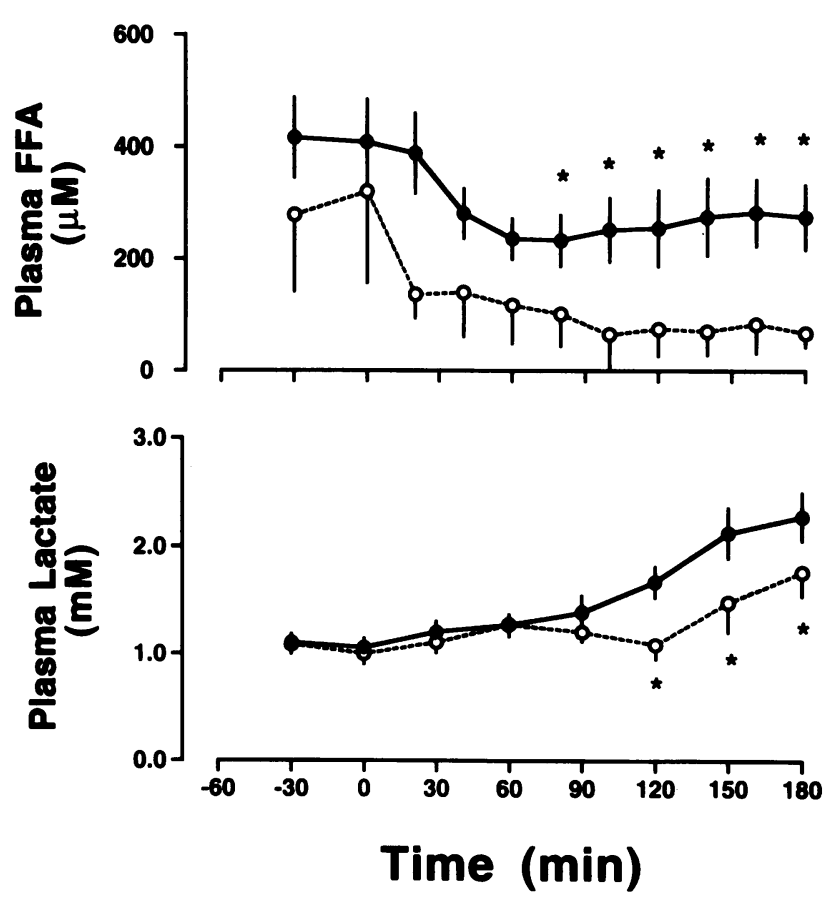

Figure 5. Plasma FFA and lactate concentrations in controls $(0)$ and NIDDM $(\bullet)$. Plasma FFA was higher at baseline in NIDDM $(P$ $=\mathrm{NS})$ and did not decline as in controls $\left({ }^{*} P<0.001\right)$. Plasma lactate concentrations in the two groups were identical at baseline and during euglycemia, but in the last 60 min of study plasma lactate continued to increase in NIDDM but remained lower in controls $\left({ }^{*} P<0.01\right)$. 

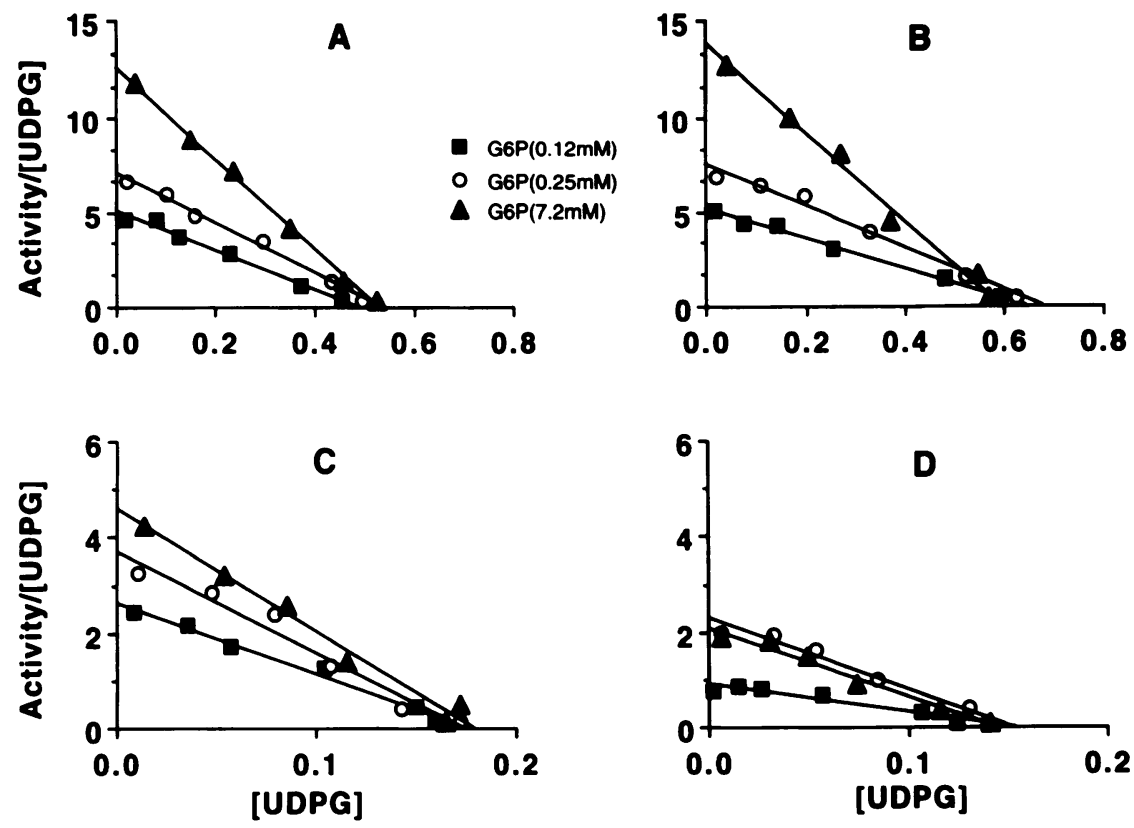

Figure 6. Eadie-Hofstee plots of glycogen synthase activity during euglycemia $(A)$ and hypoglycemia $(B)$ in a representative control subject, and during euglycemia $(C)$ and hypoglycemia $(D)$ in a NIDDM subject. Note the difference in ordinate scales for the two subjects, denoting the decreased glycogen synthase activity present at baseline in NIDDM. Plots show experiments conducted at 3 different in vitro concentrations of G-6-P ( see text for details).

did not rise above the basal level in NIDDM and it was twofold higher in the nondiabetic subjects than in NIDDM. In these moderately controlled NIDDM, the counterregulatory hormonal response to mild hypoglycemia was characterized by a blunted plasma glucagon increment and by an earlier, augmented rise in plasma epinephrine compared with controls.
Plasma FFA and lactate concentrations were also significantly higher in NIDDM during hypoglycemia. Hypoglycemia was associated with marked inhibition of skeletal muscle glycogen synthase activity and an increase in glycogen phosphorylase in NIDDM, but not in controls. These coordinated changes in enzyme activities resulted in a fivefold increase in the intracel-

\section{Euglycemia \\ Hypoglycemia}
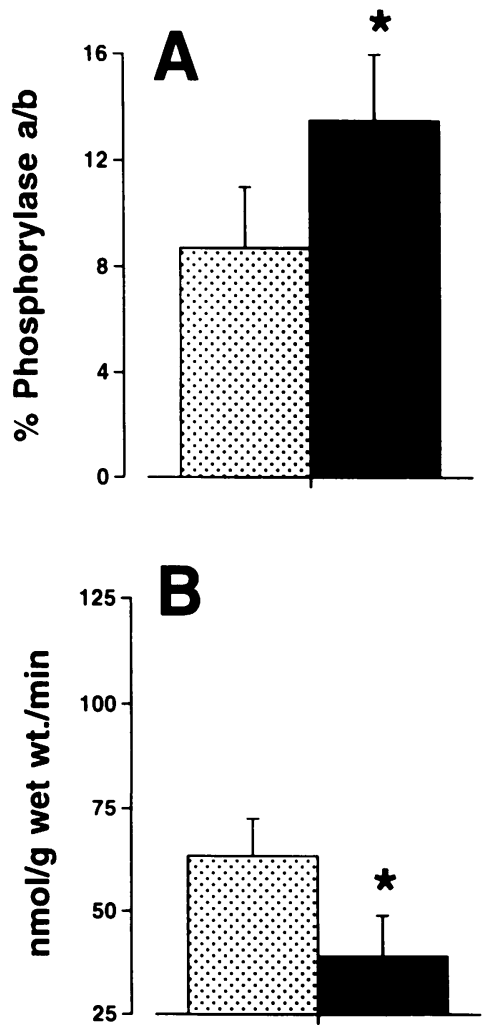

NIDDM
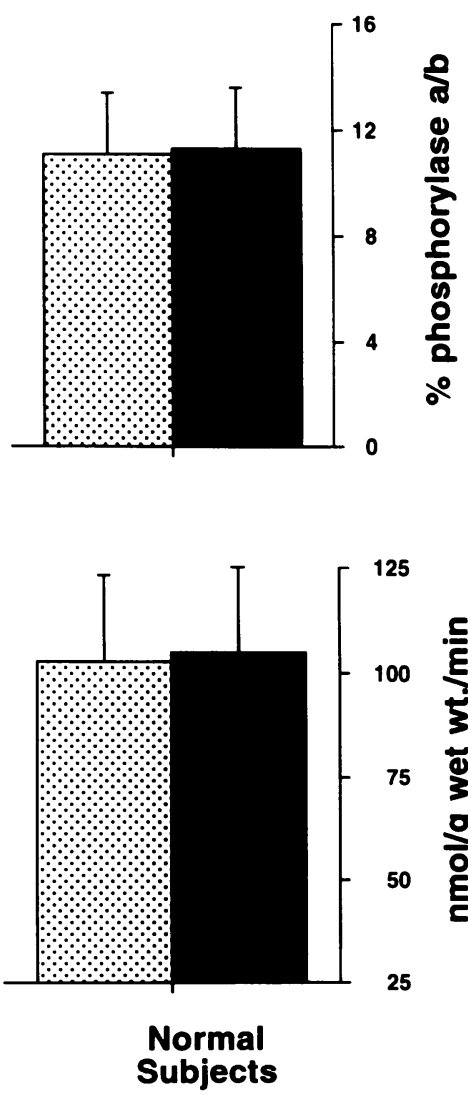

Figure 7. (A) Skeletal muscle glycogen phosphorylase activities during euglycemia and hypoglycemia in NIDDM and controls. During euglycemic hyperinsulinemia, enzyme activities were similar in the 2 groups. In NIDDM only, there was a significant $\left({ }^{*} P\right.$ $<0.01)$ increase in activity after hypoglycemia. $(B)$ Skeletal muscle glycogen synthase activities at mid-physiologic concentrations of G-6-P $(110 \mu \mathrm{M})$ and UDPG ( $33 \mu \mathrm{M})$ (see text). During hypoglycemia, glycogen synthase activity in NIDDM fell by $42 \%$ $\left({ }^{*} P<0.01\right)$ while no decline was seen in controls. 


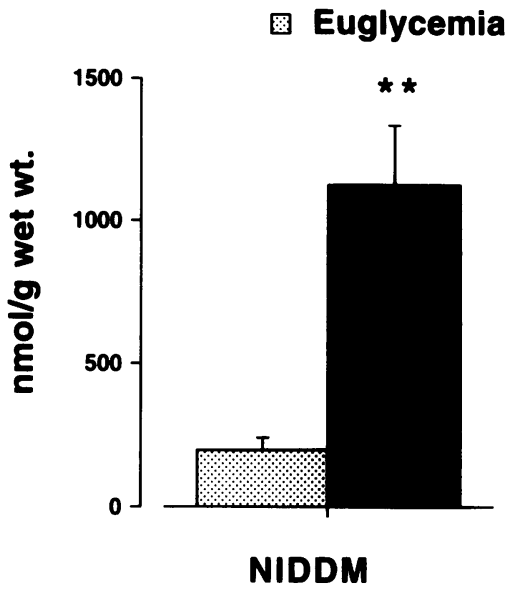

NIDDM

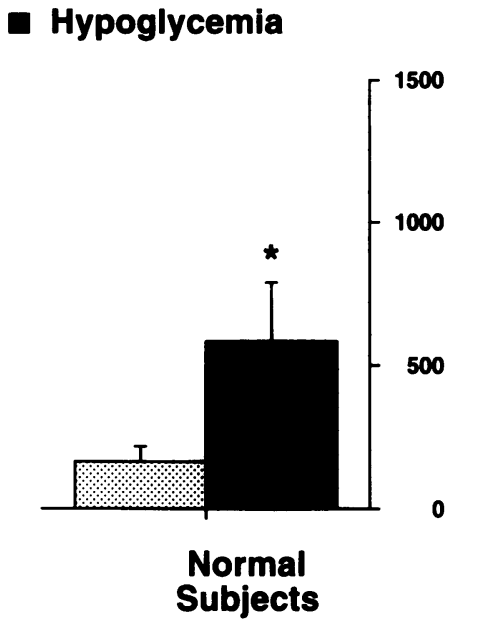

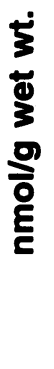

Figure 8. Skeletal muscle G-6-P concentrations in NIDDM and controls during euglycemia and hypoglycemia. During euglycemic hyperinsulinemia, G-6-P concentrations were similar in the two groups. However, during hypoglycemia, there was a fivefold increase in G-6-P concentrations in NIDDM that exceeded the rise in controls by approximately twofold $\left({ }^{*} P<0.05\right.$, controls, euglycemia vs. hypoglycemia; ${ }^{* *} P<0.01$, NIDDM vs. controls, hypoglycemia). lular G-6-P concentrations in NIDDM, despite decreased glucose uptake. In contrast, though controls displayed a 10-fold increase in plasma epinephrine during hypoglycemia, there was no significant change in skeletal muscle glycogen phosphorylase or synthase activities and only a modest rise in G-6-P concentrations. Since the rates of peripheral glucose uptake were markedly decreased in the NIDDM subjects and the rate of plasma glucose entering glycolysis was equivalent in the two groups, it is likely that decreased glycogen formation and/or increased glycogen breakdown were the sites that ultimately resulted in the increased intracellular muscle G-6-P. The latter, in turn, may have caused decreased glucose phosphorylation and increased carbon flux through glycolysis. Consistent with this interpretation, the plasma lactate concentrations rose to a greater extent during hypoglycemia in NIDDM than in controls.

Counterregulatory hormone responses. The secretion of counterregulatory hormones in this group of NIDDM subjects differed in several important respects from the pattern reported in IDDM (1). In particular, hypoglycemia triggered a modest glucagon response in NIDDM, although not commensurate with that observed in nondiabetic controls. However, in contrast to the notion that $\alpha$-cell secretion during hypoglycemia is intact in NIDDM (30), our results are consistent with the re-

Table II. Kinetic Analysis of Skeletal Muscle Glycogen Synthase during Euglycemic Hyperinsulinemia (EU) and Hypoglycemic Hyperinsulinemia (HYPO) in Nondiabetic Controls and NIDDM Subjects

\begin{tabular}{|c|c|c|c|c|c|}
\hline & \multirow[b]{2}{*}{ G-6-P } & \multicolumn{2}{|c|}{$K_{\mathrm{m}}$} & \multicolumn{2}{|c|}{$V_{\max }$} \\
\hline & & EU & HYPO & EU & HYPO \\
\hline & $m M$ & \multicolumn{2}{|c|}{$m M$} & \multicolumn{2}{|c|}{$\mu \mathrm{mol} / \mathrm{g}$ wet wt per minute } \\
\hline \multirow[t]{3}{*}{ Controls } & 0.11 & $0.16 \pm 0.03$ & $0.20 \pm 0.04$ & $0.49 \pm 0.08$ & $0.57 \pm 0.08$ \\
\hline & 0.22 & $0.10 \pm 0.02$ & $0.13 \pm 0.03$ & $0.50 \pm 0.13$ & $0.58 \pm 0.08$ \\
\hline & 7.2 & $0.06 \pm 0.01$ & $0.07 \pm 0.02$ & $0.52 \pm 0.08$ & $0.57 \pm 0.07$ \\
\hline \multirow[t]{3}{*}{ NIDDM } & 0.11 & $0.15 \pm 0.02$ & $0.28 \pm 0.04^{*}$ & $0.25 \pm 0.05$ & $0.28 \pm 0.06$ \\
\hline & 0.22 & $0.09 \pm 0.01$ & $0.17 \pm 0.02^{*}$ & $0.26 \pm 0.05$ & $0.29 \pm 0.07$ \\
\hline & 7.2 & $0.06 \pm 0.02$ & $0.09 \pm 0.02^{*}$ & $0.26 \pm 0.06$ & $0.28 \pm 0.06$ \\
\hline
\end{tabular}

${ }^{*} P<0.01$ HYPO vs. EU. port by Bolli et al. (5) using a comparable design that suggest that there may indeed be defective glucagon secretion. The mechanism of this defect in NIDDM remains uncertain. There was no relationship in our subjects between factors such as the duration of diabetes and the type of treatment on the glucagon response. Moreover, although it has been reported that prolonged hyperinsulinemia may attenuate hypoglycemia-induced glucagon secretion $(31,32)$, the present results show that neither the degree nor duration of similar insulin infusions during the clamps prevented the glucagon response in controls. Nevertheless, overnight insulinization in the NIDDM or other factors may contribute to the lack of a glucagon response.

In IDDM, since the plasma glucagon response to hypoglycemia is normal at the onset of diabetes but is progressively diminished with the duration of the disease (33), it is conceivable that this is an acquired defect that develops subsequent to $\beta$-cell failure. Recent evidence suggests that chronic hyperglycemia per se may be involved in the progressive loss of glucagon response. In fact, defective glucagon responses to hypoglycemia have also been described in several animal models of diabetes. Perhaps more importantly, Starke et al. (34) reported a restoration of the glucose-induced inhibition of the high glucagon concentrations in alloxan-diabetic dogs, after short-term ( $48 \mathrm{~h})$ phlorizin-induced normoglycemia, and Marynissen et al. (35) found a paradoxical decrease in glucagon release in vitro in response to a decreased glucose concentration perfusing isolated pancreata from normal rats made hyperglycemic for $48 \mathrm{~h}$ by glucose infusion. Hetenyi et al. (36) also reported an improvement in glucoregulation in alloxan-diabetic dogs after phlorizin treatment; however, short-term correction of hyperglycemia with phlorizin did not normalize the glucagon response to hypoglycemia, but restored the defective increase in HGO.

In contrast to glucagon, the magnitude of the plasma epinephrine response in NIDDM was severalfold that in controls. The most likely explanation for this observation is a parallel with reports that suggest that poor glycemic control may lower the glucose concentration required to trigger epinephrine secretion in IDDM (37). Though we did not specifically examine the glycemic threshold for hormone release in this study, it should be noted that plasma epinephrine was higher at baseline as euglycemia was induced in NIDDM, and a number of experiments suggest that the magnitude of the adrenomedullary response to hypoglycemia is proportional to the basal concentra- 
tion of the hormone. This explanation fails to account for the lack of similar "resetting" of the glycemic thresholds for other counterregulatory hormones, although in prior studies in IDDM the phenomenon is by no means applicable to all counterregulatory hormones (37). Regardless of the cause of this robust epinephrine response, and absent any data to suggest that the hormone's biologic effect is attenuated, we believe that this response is a critical component of the metabolic changes during hypoglycemia in NIDDM. Finally, in addition to circulating plasma epinephrine, hypoglycemia may have also augmented autonomic neural responses mediated by norepinephrine, although the magnitude of the plasma norepinephrine response was similar in the two groups.

Hepatic glucose output. Despite marked hyperinsulinemia and the lack of increase in the plasma glucagon levels, the NIDDM subjects were able to increase their HGO. The most immediate explanation is that the markedly increased plasma epinephrine response largely compensated for the lack of glucagon effect. However, the elevated plasma FFA and lactate concentrations may also have contributed to the hepatic response in NIDDM. In fact, several in vitro (38) and in vivo $(39,40)$ studies support the notion that the amount of FFA supplied to the liver may modulate hepatic gluconeogenesis (41) and its suppressibility by insulin (42). In addition, plasma FFA may modulate glucose uptake in muscle via the glucosefatty acid cycle first proposed by Randle et al. (43).

Evidence supports the hypothesis that insulin may suppress HGO through an indirect or extrahepatic mechanism: $(a)$ peripheral insulin administration is as or more effective as portal insulin in the inhibition of $\mathrm{HGO}(44,45) ;(b)$ the time-course of the insulin-mediated peripheral and hepatic actions are identical (46); and (c) correction of the impaired insulin-mediated reduction in FFA levels in NIDDM restores hepatic sensitivity to normal (47). Jahoor et al. (48) have recently shown that in normal humans a decrease in the rate of lipolysis during fasting regulates $\mathrm{HGO}$ by its effect on the availability of glycerol for gluconeogenesis. Similarly, changes in lactate, alanine, and pyruvate availability have been shown to modulate the rate of gluconeogenesis under several experimental conditions (49). Their effect on HGO greatly depends on the presence of concomitant active glycogenolysis (50) and on the hormonal signals presented to the liver (51). Under conditions of prolonged hypoglycemia, gluconeogenesis is expected to represent the major portion of hepatic glucose release (52) and the hormonal signals, particularly increased plasma epinephrine and glucagon concentrations, favor an increase in HGO. Consistent with this hypothesis, Lecavalier et al. (53) have demonstrated a decrease in HGO during hypoglycemia when they inhibited gluconeogenesis.

Although we did not directly evaluate gluconeogenesis, our results implicate peripheral tissues in glucose counterregulation in NIDDM. During hypoglycemia, it is likely that carbons are transferred from large peripheral storage pools to the liver in order to provide energy and substrates for gluconeogenesis. Lactate is a major gluconeogenic precursor in humans (7) and $\sim 60 \%$ of the plasma lactate pool is derived from glycolysis of glycogen carbons $(6,8)$. Thus, the insulin-induced inhibition of net skeletal muscle glycogenolysis may modulate the hepatic (gluconeogenic) response to hypoglycemia through the decreased transfer of 3-carbon compounds from muscle to liver; hypoglycemia may represent one of the metabolic conditions in which peripheral regulation of substrate availability for gluconeogenesis plays a major role in the modulation of overall HGO.

Glucose uptake and skeletal muscle enzyme activities. We (2) and others (5) have suggested that the impairment of the liver's ability to release glucose during hypoglycemia due to defects in glucagon and epinephrine secretion in IDDM is partially offset by reduction in whole-body glucose disposal. We hypothesize that such a compensatory action $(a)$ probably occurs in skeletal muscle, the largest compartment accounting for insulin-mediated glucose uptake, and $(b)$ may be one mechanism that could mitigate the lack of substrate (glucose) available for the brain. Bolli et al. (5) hypothesized that a reduction in whole-body glucose uptake also played a role in hypoglycemia counterregulation in NIDDM (5), but did not directly examine the role of skeletal muscle in this formulation.

The skeletal muscle ("counterregulatory") response to hypoglycemia may be defined as the sum of the reduction in glucose uptake compared with the effect of insulin alone during euglycemia and of the mobilization of gluconeogenic substrates from glycogen stores. The adipose tissue response to hypoglycemia consists of enhanced lipolysis with resulting increased availability of glycerol and FFA. Their contribution to increased HGO and decreased peripheral glucose uptake during hypoglycemia may differ in healthy volunteers and NIDDM subjects. Our data are consistent with the observations of Bolli et al. (5) and indicate a major role for the limitation of peripheral glucose uptake to compensate for the decreased glucagon response to hypoglycemia in NIDDM. In fact, the resistance to the antilipolytic effect of insulin may provide a protective mechanism against hypoglycemia by reducing insulin-stimulated glucose oxidation (thus, decreasing glucose disposal and/or increasing glycolysis to lactate) and by stimulating hepatic gluconeogenesis, through the combined effects of enhanced FFA and glycerol availability (53-56).

The balance of glycogen synthase and phosphorylase activities determines net glycogen flux in muscle. Net glycogen flux, by changing G-6-P concentration, may be pivotal for glucose uptake and for hepatic gluconeogenic substrate availability from glycolysis in muscle. During insulin-induced hypoglycemia, glycogen metabolism is regulated by the opposing signals of insulin and epinephrine. Although insulin does not directly decrease glycogen phosphorylase activity in skeletal muscle, it is noteworthy that epinephrine can increase its activity and insulin can antagonize the cAMP-mediated activation of glycogen phosphorylase (57-59). The effect of insulin-induced hypoglycemia on muscle glycogen phosphorylase has not been previously examined in humans. Our results in healthy volunteers suggest that, at high insulin concentrations, there is no detectable activation of glycogen phosphorylase during hypoglycemia. However, hypoglycemia stimulated the glycogen phosphorylase in insulin-resistant skeletal muscle of NIDDM subjects. This may be due to the decreased effect of insulin on the c-AMP-dependent protein kinase $(57,58)$ in NIDDM. Finally, in view of the greater plasma epinephrine response in NIDDM, it is likely that the same magnitude of epinephrine secretion in controls would have had similar effects (e.g., had the hypoglycemic stimulus been more intense). This would be in keeping with an in vitro effect of epinephrine to activate the glycogen synthase c-AMP-dependent protein kinase $(58,59)$.

Furthermore, we recently proposed that skeletal muscle glycogen synthase plays a central role in the regulation of glycogen balance even in the absence of net glycogen deposition 
(60). It is therefore conceivable that the activity of glycogen synthase modulates net skeletal muscle glycogenolysis and the decrease in its activity during hypoglycemia favors an increased mobilization of glucosyl units from muscle glycogen.

The measurement of skeletal G-6-P may help to define the rate-limiting step (s) of insulin action in humans under normoglycemic and hypoglycemic conditions. In fact, if glucose transport / phosphorylation were rate limiting for muscle glucose disposal during hypoglycemic hyperinsulinemia, G-6-P concentrations should have fallen compared with euglycemia. Conversely, if a distal intracellular step were rate limiting, G-6$P$ should have increased during the hypoglycemic insulin clamp. The marked increase in muscle G-6-P levels we observed during hypoglycemia suggests that the major site of "skeletal muscle counterregulation" is distal to glucose phosphorylation, most probably at the level of glycogen synthesis/ breakdown.

In conclusion, impaired peripheral insulin sensitivity in NIDDM appears to influence hypoglycemia counterregulation through at least two major mechanisms: ( $a$ ) a "direct" mechanism, i.e., decrease in peripheral (muscle) glucose disposal; $(b)$ an "indirect" mechanism, i.e., increased substrate availability for hepatic gluconeogenesis, by lipolysis and skeletal muscle glycogenolysis. This indirect mechanism(s) may be of particular importance in diabetes, where gluconeogenesis is substantially increased and where it may play the predominant role in the hepatic response to hypoglycemia. Our results support the hypothesis that during hypoglycemia skeletal muscle glycogen mobilization and lipolysis contribute to the metabolic response to hypoglycemia more so in NIDDM than in controls.

\section{Acknowledgments}

The authors are grateful to Robin Sgueglia, B.S., and Kathleen Howard, B.A., for excellent technical assistance, and to Anne Thomashunis, R.N., for expert assistance with the clamp studies. The authors also acknowledge the valuable critique of the manuscript by Dr. Norman Fleischer.

This work was supported by grants from the American Diabetes Association and the National Institutes of Health (R01-DK-47477 and R029-DK 42177), the Juvenile Diabetes Foundation (1911127), and by the Core Laboratories of the Albert Einstein DRTC (DK 20541).

\section{References}

1. Cryer, P. E. 1993. Iatrogenic hypoglycemia in IDDM. Consequences, risk factors and prevention. In Diabetes Annual, Vol. 7. S. M. Marshall, P. D. Home, K. G. M. M. Alberti, L. Krall, editors. Elsevier Science Publishers, Amsterdam, 317-331.

2. Kleinbaum, J., and H. Shamoon. 1983. Impaired counterregulation of hypoglycemia in insulin-dependent diabetes mellitus. Diabetes. 32:493-498.

3. DeFronzo, R. A. 1988. The triumvirate: B-cell, muscle, liver. A collusion responsible for NIDDM. Diabetes. 37:667-687.

4. Yki-Jarvinen, H., M. Kauppila, E. Kujansuu, J. Lahti, T. Marjanen, L. Niskanen, S. Rajala, L. Ryysy, S. Salo, and P. Sappala. 1992. Comparison of insulin regimens in patients with non-insulin-dependent diabetes mellitus. $N$. Engl. J. Med. 327:1426-1433.

5. Bolli, G. B., E. Tsalikian, M. W. Haymond, P. E. Cryer, and J. E. Gerich. 1984. Defective glucose counterregulation after subcutaneous insulin in noninsulin dependent diabetes mellitus. J. Clin. Invest. 73:1532-1541.

6. Consoli, A., N. Nurjhan, J. J. Reilly, Jr., D. M. Bier, and J. E. Gerich. 1990. Mechanisms of increased gluconeogenesis in noninsulin dependent diabetes mellitus. J. Clin. Invest. 87:2083-2045.

7. Gerich, J., M. Haymond, R. Rizza, C. Verdonk, and J. Miles. 1981. Hormonal and substrate determinants of hepatic glucose production in man. In The Regulation of Carbohydrate Formation and Utilization in Mammals. C. Veneziale, editor. University Park Press, Baltimore, 419-457.
8. Virkamaki, A., I. Puhaikainen, N. Nurjhan, J. E. Gerich, and H. Yki-Jarvinen. 1990. Measurement of lactate formation from glucose using $\left[6-{ }^{3} \mathrm{H}\right]$ and $\left[6-{ }^{14} \mathrm{C}\right]$ glucose in humans. Am. J. Physiol. 259:E397-E404.

9. Magnusson, I., D. L. Rothman, L. D. Katz, R. G. Shulman, and G. I. Shulman. 1992. Increased rate of gluconeogenesis in type II diabetes mellitus. A ${ }^{13} \mathrm{C}$ nuclear magnetic resonance study. J. Clin. Invest. 90:1323-1327.

10. Davis, M., and H. Shamoon. 1991. Adaptive counterregulatory responses to hypoglycemia in nondiabetic humans. J. Clin. Endocrinol. Metab. 73:9951001 .

11. Bergstrom, J., and E. Hultman. 1967. A study of the glycogen metabolism during exercise in man. Scand. J. Clin. Lab. Invest. 19:218-228.

12. Kuzuya, H., P. M. Blix, D. L. Horwitz, D. F. Steiner, and A. M. Rubenstein. 1977. Determination of free and total insulin and C-peptide in insulintreated diabetics. Diabetes. 26:22-29.

13. Sotsky, M. J., S. Shilo, and H. Shamoon. 1989. Regulation of counterregulatory hormone secretion in man during exercise and hypoglycemia. J. Clin. Endocrinol. Metab. 68:9-16.

14. Shilo, S., M. Sotsky, and H. Shamoon. 1990. Islet hormonal regulation of glucose turnover during exercise in type 1 diabetes. J. Clin. Endocrinol. Metab. 70:162-172.

15. Gawehn, K. D-lactate. 1986. In Methods of Enzymatic Analysis. H. Bergmeyer and M. Gassl, editors. VI:583-592.

16. Steele, R. R. 1959. Influence of glucose loading and of insulin on hepatic glucose output. Ann. NY Acad. Sci. 82:420-430.

17. Finegood, D. T., R. N. Bergman, and M. Vranic. 1987. Estimation of endogenous glucose production during hyperinsulinemic-euglycemic glucose clamp: comparison of unlabeled and labeled glucose infusates. Diabetes. 36:914924.

18. Young, A. A., C. Bogardus, D. Wolfe-Lopez, and D. M. Mott. 1988. Muscle glycogen synthesis disposition of infused glucose in humans with reduced rates of insulin-mediated carbohydrate storage. Diabetes. 37:303-308.

19. Rossetti, L., and A. Giaccari. 1990. Relative contribution of glycogen synthesis and glycolysis to insulin-mediated glucose uptake. A dose-response euglycemic clamp study in normal and diabetic rats. J. Clin. Invest. 85:1785-1792.

20. Hostler, K. Y., and B. R. Landau. 1967. Estimation of the pentose cycle contribution to glucose metabolism in tissue in vivo. Biochemistry. 6:2961-2964.

21. Karlander, S., A. Roovete, M. Vranic, and S. Efendic. 1986. Glucose and fructose-6-phosphate cycle in humans. Am. J. Physiol. 251:E530-E536.

22. Spence, J. T., and A. P. Koudelka. 1985. Pathway of glycogen synthesis from glucose in hepatocytes maintained in primary culture. J. Biol. Chem. 260:1521-1526

23. Rossetti, L., Y.-T. Lee, J. Ruiz, S. Aldridge, H. Shamoon, and G. Boden. 1993. Quantitation of glycolysis and skeletal muscle glycogen synthesis in humans. Am. J. Physiol. 265:E761-E769.

24. Michal, G. 1985. D-Glucose-6-Phosphate. In Methods of Enzymatic Analysis. Vol. VI, H. U. Bergmeyer, editor. VCH Publishers, Weinheim, 191-198.

25. Rossetti, L., and M. R. Laughlin. 1989. Correction of chronic hyperglycemia with vanadate, but not phlorizin, normalizes in vivo glycogen repletion and in vitro glycogen synthase activity in diabetic skeletal muscle. J. Clin. Invest. 84:892-899.

26. Farrace, S., and Rossetti, L. 1992. Hyperglycemia markedly enhances skeletal muscle glycogen synthase activity in diabetic, but not in normal conscious rats. Diabetes. 41:1453-1463.

27. Thomas, J. A., K. K. Schlender, and J. Larner. 1968. A rapid filter paper assay for UDP-glucose-glycogen glucosyltransferase, including an improved biosynthesis for UDP $\left({ }^{14} \mathrm{C}\right)$ glucose. Anal. Biochem. 25:486-499.

28. Rossetti, L., S. Farrace, S. B. Choi, A. Giaccari, L. Sloan, S. Frontoni, M. S. Katz. 1993. Multiple metabolic effects of calcitonin gene-related peptide (CGRP) in conscious rats. Relationship to its regulation of glycogen synthase and adenylate cyclase. Am. J. Physiol. 264:E1-E10.

29. Zar, J. H. 1983. Biostatistical Analysis. 2nd ed. Prentice Hall, Englewood Cliffs, NJ, 110-114, 162-165.

30. Gerich, J. E., M. Langlois, C. Noacco, J. H. Karam, and P. H. Forsham. 1973. Lack of glucagon response to hypoglycemia in diabetics. Science (Wash. DC). 182:171-173.

31. Mellman, M., M. Davis, and H. Shamoon. 1992. Effect of physiologic hyperinsulinemia on counterregulatory hormone responses during hypoglycemia in humans. J. Clin. Endocrinol. Metab. 75:1293-1297.

32. Liu, D., E. Moberg, M. Kollind, P. E. Lins, and U. Adamson. 1991. A high concentration of circulating insulin suppresses the glucagon response to hypoglycemia in normal man. J. Clin. Endocrinol. Metab. 73:1123-1128.

33. Unger, R. H. 1983. The Berson Memorial Lecture. Insulin-glucagon relationships in the defense against hypoglycemia. Diabetes. 32:575-583.

34. Starke, A., S. Grundy, J. D. McGarry, and R. H. Unger. 1985. Correction of hyperglycemia with phlorizin restores the glucagon response to glucose in insulin-deficient dogs: implications for human diabetes. Proc. Natl. Acad. Sci. USA. 82:1544-1546.

35. Marynissen, G., V. Leclercq-Meyer, A. Sener, and W. J. Malaisse. 1990. Perturbation of pancreatic islet function in glucose-infused rats. Metab. Clin. Exp. 39:87-95. 
36. Hetenyi, G., Jr., C. Gauthier, M. Byers, and M. Vranic. 1989. Phlorizininduced normoglycemia partially restores glucoregulation in diabetic dogs. $\mathrm{Am}$. J. Physiol. 256:E277-E283.

37. Boyle, P. J., N. S. Schwartz, S. D. Shah, W. E. Clutter, and P. E. Cryer 1988. Plasma glucose concentrations at the onset of hypoglycemic symptoms in patients with poorly-controlled diabetes and nondiabetics. N. Engl. J. Med. 318:1487-1492.

38. Herrera, M. G., D. Kamm, N. Ruderman, and G. F. Cahill. 1966. Nonhormonal factors in the control of gluconeogenesis. Adv. Enzyme Regul. 4:225235.

39. Ruderman, N. B., C. J. Toews, and E. Shafrir. 1969. Role of free fatty acids in glucose homeostasis. Arch. Intern. Med. 123:299-313.

40. Ferrannini, E., E. J. Barrett, S. Bevilacqua, and R. A. DeFronzo. 1983. Effect of fatty acids on glucose production and utilization in man. J. Clin. Invest. 72:1737-1747.

41. Williamson, J. R., R. A. Kriesberg, and P. W. Felts. 1966. Mechanism for the stimulation of gluconeogenesis by fatty acids in the perfused rat liver. J. Biol. Chem. 244:4095-4102.

42. Golay, A., A. L. M. Swislocki, Y.-D. Chen, and G. M. Reaven. 1987. Relationships between free fatty acid concentration endogenous glucose production and fasting hyperglycemia in normal and noninsulin dependent diabetic individuals. Metab. Clin. Exp. 36:692-696.

43. Randle, P. J., P. G. Garland, C. N. Hales, and E. A. Newsholme. 1963. The glucose-fatty acid cycle. Its role in insulin sensitivity and the metabolic disturbances of diabetes. Lancet. i:785-89.

44. Ader, M., and R. Bergman. 1990. Peripheral effects of insulin dominate suppression of fasting hepatic glucose production. Am. J. Physiol. 245:E1020 E1032.

45. Giacca, A., F. S. Fisher, R. Gupta, Z. Shi, L. Lickley, and M. Vranic. 1992. Importance of peripheral mechanisms of insulin action for the regulation of hepatic glucose production in depancreatectomized dogs. J. Clin. Invest. 90:17691777.

46. Bradley, D. C., R. A. Poulin, and R. Bergman. 1993. Dynamics of hepatic and peripheral insulin effects suggest common rate-limiting step in vivo. Diabetes. 42:296-306.

47. Saloranta, C., A. Franssila-Kallunki, A. Ekstrand, M.-R. Taskinen, and L. Groop. 1991. Modulation of hepatic glucose production by non-esterified fatty acids in type 2 (noninsulin-dependent) diabetes mellitus. Diabetologia. 34:409415 .

48. Jahoor, F., S. Klein, and R. Wolfe. 1992. Mechanisms of regulation of glucose production by lipolysis in humans. Am. J. Physiol. 262:E353-E358.

49. Exton, J., L. Mallette, L. Jefferson, E. Wong, N. Friedman, T. Miller, and C. R. Park. 1970. The hormonal control of hepatic gluconeogenesis. Recent Prog. Horm. Res. 26:411-455.

50. Jennsen, T., N. Nurjhan, A. Consoli, and J. E. Gerich. 1990. Failure of substrate-induced gluconeogenesis to increase overall glucose appearance in normal humans. J. Clin. Invest. 86:489-497.

51. Garber, A., D. Bier, P. Cryer, and A. Pagliaro. 1976. Hypoglycemia in compensated chronic renal insufficiency: substrate limitation of gluconeogenesis. Diabetes. 23:982-986.

52. Frizzell, R., G. Hendrick, D. Biggers, D. Lacy, D. Donahue, D. Green, R. Carr, P. Williams, R. Stevenson, and A. Cherrington. 1988. Role of gluconeogenesis in sustaining glucose production during hypoglycemia caused by continuous insulin infusion in conscious dogs. Diabetes. 37:749-759.

53. Lecavalier, L., G. Bolli, P. Cryer, and J. Gerich. 1989. Contributions of gluconeogenesis and glycogenolysis during glucose counterregulation in normal humans. Am. J. Physiol. 256:E844-E451.

54. Caprio, S., R. A. Gelfand, W. V. Tamborlane, and R. S. Sherwin. 1989. Oxidative fuel metabolism during mild hypoglycemia: critical role of free fatty acids. Am. J. Physiol. 256:E413-E419.

55. Fanelli, C., S. Calderone, L. Epifano, A. De Vincenzo, F. Mondarelli, S. Pampanelli, G. Perriello, P. De Feo, P. Brunetti, J. E. Gerich, et al. 1993. Demonstration of a critical role for free fatty acids in mediating counterregulatory stimulation of gluconeogenesis and suppression of glucose utilization in humans. $J$. Clin. Invest. 92:1617-1622.

56. Caprio, S., S. Amiel, W. V. Tamborlane, R. A. Gelfand, and R. S. Sherwin. 1990. Defective free-fatty acid and oxidative glucose metabolism in IDDM during hypoglycemia. Diabetes. 39:134-141.

57. Yki-Jarvinen, H., D. Mott, A. A. Young, K. Stone, and C. Bogardus. 1987. Regulation of glycogen synthase and phosphorylase activities by glucose and insulin in human skeletal muscle. J. Clin. Invest. 80:95-100.

58. Parker, P. J., F. B. Caudwell, and P. Cohen. 1982. Glycogen synthase from rabbit skeletal muscle: effect of insulin on the state of phosphorylation of the seven phosphoserine residues in vivo. Eur. J. Biochem. 130:227-230.

59. Roach, P. J., and J. Larner. 1976. Rabbit skeletal muscle glycogen synthase. II. Enzyme phosphorylation state and effector concentrations as interacting control parameters. J. Biol. Chem. 251:1920-1925.

60. Rossetti, L., and M. Hu. 1993. Skeletal muscle glycogenolysis is more sensitive to insulin than is glucose transport/phosphorylation. J. Clin. Invest. 92:2963-2974. 